\title{
Differentiation of susceptibility levels of oilseed rape pests to the same active substances of insecticides on the example of pollen beetle and cabbage seed weevil
}

\author{
Zróżnicowanie poziomów wrażliwości szkodników rzepaku \\ na te same substancje czynne insektycydów \\ na przykładzie słodyszka rzepakowego i chowacza podobnika
}

Joanna Zamojska, Paweł Węgorek, Paweł Olejarski, Marek Mrówczyński

Summary

Pollen beetle (Meligethes aeneus F.) and cabbage seed weevil (Ceutorhynchus assimilis Payk.) occur very often at the same time in winter and spring oilseed rape in Polish climatic conditions. The aim of the study was to determine the susceptibility of pollen beetle and cabbage shoot weevil to the same, selected active substances of insecticides from the group of pyrethroids, organophosphates and neonicotinoids recommended in Poland. The studies were conducted with the use of contact-stomach method, which involves tested beetles exposition to treated leaves and inflorescences of host plants. The results indicated high or very high pollen beetle resistance to pyrethroid active substances (the exception was tau-fluwaliant to which the pest showed susceptibility or weak resistance) and some level of cabbage seed weevil resistance to neonicotinoids. The results clearly indicate that the protection of oilseed rape in Poland requires continuous monitoring of resistance level of both pests and regular update of control programs for both species.

Key words: spring rape; winter oilseed rape; cabbage shoot weevil; pollen beetle; insecticide resistance

\begin{abstract}
Streszczenie
W warunkach klimatycznych Polski, na rzepaku ozimym i jarym, bardzo często występują równocześnie dwa groźne dla tej rośliny szkodniki - słodyszek rzepakowy (Meligethes aeneus F.) i chowacz podobnik (Ceutorhynchus assimilis Payk.). Celem badań było określenie wrażliwości słodyszka rzepakowego i chowacza podobnika na wybrane substancje czynne insektycydów z grupy pyretroidów, związków fosforoorganicznych oraz neonikotynoidów, zalecane w Polsce. Doświadczenia przeprowadzono metodą kontaktowo-żołądkową, polegającą na eksponowaniu badanych chrząszczy na traktowane chemicznie liście i kwiatostany roślin żywicielskich. Wyniki doświadczeń wykazały wysoką lub bardzo wysoką odporność słodyszka rzepakowego na substancje czynne z grupy pyretroidów (wyjątek stanowił tau-fluwalinat, na który szkodnik wykazywał wrażliwość lub słabą odporność) oraz pewien poziom odporności chowacza podobnika na neonikotynoidy. Uzyskane wyniki wyraźnie wskazują, że ochrona rzepaku w Polsce wymaga stałego monitorowania poziomu odporności obu szkodników i na tej podstawie opracowywania strategii ich zwalczania.
\end{abstract}

Słowa kluczowe: rzepak jary; rzepak ozimy; chowacz podobnik; słodyszek rzepakowy; odporność na insektycydy

Instytut Ochrony Roślin - Państwowy Instytut Badawczy

Władysława Węgorka 20, 60-318 Poznań

j.zamojska@iorpib.poznan.pl 


\section{Wstęp / Introduction}

Ochrona insektycydowa rzepaku ozimego i jarego w Polsce, a także w innych państwach Unii Europejskiej, napotyka wiele trudności ze względu na dużą liczbę gatunków szkodników, rokrocznie przekraczających znacznie progi szkodliwości i występujących w tym samym czasie na plantacji (Mrówczyński i Pruszyński 2008). Stwarza to konieczność równoczesnego ich zwalczania. Różne gatunki wykazują zróżnicowane poziomy wrażliwości na te same substancje czynne insektycydów, co powoduje, że pewna część zwalczanej populacji przeżywa zabieg i powoduje straty plonu (Heimbach i wsp. 2006a, b; Nauen 2007; Mrówczyński i wsp. 2009; Węgorek i wsp. 2009; Zamojska i wsp. 2010). W warunkach klimatycznych Polski bardzo często na rzepaku ozimym i jarym równocześnie występują dwa groźne dla tej rośliny szkodniki - słodyszek rzepakowy (Meligethes aeneus F.) i chowacz podobnik (Ceutorhynchus assimilis Payk.). Straty powodowane przez te gatunki mogą być znaczne, również ze względu na narastające zjawisko ich odporności. W Polsce do zwalczania wymienionych szkodników rzepaku zaleca się szereg insektycydów z grup chemicznych: pyretroidów, związków fosforoorganicznych oraz neonikotynoidów i pochodnych pirazoli. Poziom wrażliwości słodyszka rzepakowego w Polsce i innych krajach europejskich był od dawna badany i jest monitorowany nadal. Odporność tego szkodnika dotyczy aktualnie przede wszystkim insektycydów z chemicznej grupy pyretroidów (Hansen 2008; Richardson 2008; Węgorek 2009; Zamojska i wsp. 2010). W literaturze niewiele jest danych na temat poziomu wrażliwości chowacza podobnika na substancje czynne insektycydów (Heimbach i wsp. 2006a; Zamojska i wsp. 2010).

Celem prowadzonych badań było porównanie wrażliwości chowacza podobnika i słodyszka rzepakowego na te same substancje czynne insektycydów.

\section{Materiały i metody / Materials and methods}

Materiał badawczy stanowiły chrząszcze słodyszka rzepakowego i chowacza podobnika $z$ wybranych populacji na terenie Polski. Badania prowadzono w latach 2011 i 2012 na tych samych populacjach obu gatunków.

W celu testowania poziomu wrażliwości chrząszczy słodyszka rzepakowego i chowacza podobnika stosowano metodę kontaktowo-żołądkową zalecaną przez Komitet do Spraw Odporności Owadów (IRAC - Insecticide Resistance Action Committee). Metoda ta polega na eksponowaniu badanych chrząszczy na traktowanych chemicznie liściach i kwiatostanach roślin żywicielskich.

Kwiatostany wraz z liśćmi zanurzano na około 5 sekund w wodnych roztworach insektycydów i po ich wysuszeniu umieszczano w słojach o pojemności 0,91 . Następnie do każdego słoja wkładano po 100 chrząszczy słodyszka rzepakowego lub po 50 chrząszczy chowacza podobnika. Dla każdej substancji czynnej stosowano 5-8 stężeń, rozcieńczając je o połowę. Każde stężenie testowano w trzech powtórzeniach dla każdej populacji. Próby kontrolne stanowiły owady naniesione na liście i kwiatostany rzepaku nietraktowane chemicznie. Śmiertelność chrząszczy kontrolowano po 24 godzinach. Notowano śmiertelność chrząszczy w procentach i na tej podstawie wyliczano dawki powodujące 50 i 95\% śmiertelności owadów ( $\mathrm{LC}_{50}$ i $\mathrm{LC}_{95}$ ). Ze stosunku $\mathrm{LC}_{95}$ do dawki zalecanej insektycydu wyliczano współczynnik odporności (WO) i na tej podstawie klasyfikowano odporność populacji.

Przyjęto następujące kryteria oceny wrażliwości populacji na insektycydy:

$\mathrm{WO} \leq 1-$ brak odporności,

$\mathrm{WO}=1,1-2-$ odporność niska,

$\mathrm{WO}=2,1-5-$ odporność średnia,

$\mathrm{WO}=5,1-10-$ odporność wysoka,

WO $>10$ - odporność bardzo wysoka.

\section{Wyniki i dyskusja / Results and discussion}

Wyniki badań wykazały wysoką lub bardzo wysoką odporność słodyszka rzepakowego na substancje czynne z grupy pyretroidów (tab. 1). Najskuteczniejszą substancją $\mathrm{z}$ tej grupy chemicznej okazał się tau-fluwalinat, na który chrząszcze słodyszka rzepakowego wykazywały wrażliwość lub słabą odporność. Zdecydowanie skuteczniejsze od pyretroidów były, w zwalczaniu słodyszka rzepakowego, substancje $\mathrm{z}$ grupy neonikotynoidów, przy czym większą wrażliwość notowano najczęściej w odniesieniu do acetamiprydu. W odniesieniu do dwóch badanych substancji z grupy neonikotynoidów (acetamipryd i tiachlopryd) słodyszek rzepakowy wykazywał wrażliwość, słabą odporność lub w przypadku tiachloprydu, odporność średnią. Wysoką wrażliwość obserwowano wyłącznie $\mathrm{w}$ odniesieniu do chloropiryfosu $\mathrm{z}$ grupy związków fosforoorganicznych. Zupełnie inaczej sytuacja wyglądała w badaniach chrząszczy chowacza posobnika (tab. 2). Badane populacje wykazywały bardzo wysoką wrażliwość na wszystkie badane substancje $\mathrm{z}$ grupy pyretroidów. Odporność chowacza podobnika zaobserwowano natomiast $\mathrm{w}$ odniesieniu do substancji $\mathrm{z}$ grupy neonikotynoidów. Uzyskane wyniki są zbieżne $\mathrm{z}$ wynikami uzyskiwanymi w latach wcześniejszych w Polsce i innych krajach europejskich (Heimbach i wsp. 2006a, b; Węgorek i wsp. 2009; Zamojska i wsp. 2010). Zaznaczyć należy, że w dotychczasowej literaturze naukowej dane na temat poziomu wrażliwości chowacza podobnika na substancje czynne insektycydów są nieliczne. W przedstawionych wynikach badań zwraca uwagę znacząco różna wrażliwość obu badanych gatunków na substancje $\mathrm{z}$ grupy pyretroidów i neonikotynoidów, co może znacznie utrudnić ochronę rzepaku w Polsce. Jest to zjawisko ciekawe $\mathrm{z}$ naukowego punktu widzenia, gdyż historia zwalczania obu gatunków, jak również obecne zalecenia są podobne (Mrówczyński i Pruszyński 2008). Występujące równocześnie na polach rzepaku chrząszcze słodyszka rzepakowego i chowacza podobnika mają najprawdopodobniej odmienny potencjał genetyczny odnośnie procesów detoksykacji metabolicznej, co nie wyklucza narastania odporności słodyszka rzepakowego na neonikotynoidy i chowacza podobnika na pyretroidy przy dalszym utrzymywaniu się podobnego nacisku selekcyjnego (Malinowski 2003). 
Tabela 1. Monitoring wrażliwości słodyszka rzepakowego w latach 2011-2012

Table 1. Pollen beetle susceptibility monitoring in the years 2011-2012

\begin{tabular}{|c|c|c|c|c|c|c|}
\hline $\begin{array}{l}\text { Substancja czynna } \\
\text { Active substance }\end{array}$ & $\begin{array}{c}\text { Wysoka } \\
\text { wrażliwość } \\
\text { High } \\
\text { susceptibility }\end{array}$ & $\begin{array}{l}\text { Wrażliwość } \\
\text { Susceptibility }\end{array}$ & $\begin{array}{c}\text { Słaba } \\
\text { odporność } \\
\text { Weak } \\
\text { resistance }\end{array}$ & $\begin{array}{l}\text { Średnia } \\
\text { odporność } \\
\text { Medium } \\
\text { resistance }\end{array}$ & $\begin{array}{l}\text { Wysoka } \\
\text { odporność } \\
\text { High } \\
\text { resistance }\end{array}$ & $\begin{array}{c}\text { Średnia śmiertelność } \\
\text { przy zalecanych } \\
\text { dawkach } \\
\text { Mean mortality at } \\
\text { recommended doses } \\
{[\%]}\end{array}$ \\
\hline Alpha-cypermethrin & & & & $\mathrm{X}$ & $\mathrm{X}$ & $45-75$ \\
\hline Beta-cyfluthrin & & & & & $X$ & $5-58$ \\
\hline Deltamethrin & & & & & $\mathrm{X}$ & $5-48$ \\
\hline Esfenvalerate & & & & $\mathrm{X}$ & $\mathrm{X}$ & $34-75$ \\
\hline Gamma-cyhalothrin & & & & & $\mathrm{X}$ & $5-45$ \\
\hline Lambda-cyhalothrin & & & & $\mathrm{X}$ & $\mathrm{X}$ & $30-82$ \\
\hline Tau-fluvalinate & & $\mathrm{X}$ & $X$ & & & $85-99$ \\
\hline Zeta-cypermethrin & & & & $\mathrm{X}$ & & $62-82$ \\
\hline Acetamiprid & & $\mathrm{X}$ & $\mathrm{X}$ & & & $82-99$ \\
\hline Tiacloprid & & $\mathrm{X}$ & $X$ & $\mathrm{X}$ & & $80-99$ \\
\hline Chlorpyrifos & $X$ & & & & & 100 \\
\hline $\begin{array}{l}\text { Tiacloprid }+ \\
\text { Deltamethrin }\end{array}$ & \multicolumn{5}{|c|}{$\begin{array}{l}\text { można określić tylko skuteczność } \\
\text { only effectiveness can be defined }\end{array}$} & $82-98$ \\
\hline
\end{tabular}

Tabela 2. Monitoring wrażliwości chowacza podobnika w latach 2011-2012

Table 2. Cabbage seed weevil susceptibility monitoring in the years 2011-2012

\begin{tabular}{|c|c|c|c|c|c|c|}
\hline $\begin{array}{l}\text { Substancja czynna } \\
\text { Active substance }\end{array}$ & $\begin{array}{c}\text { Wysoka } \\
\text { wrażliwość } \\
\text { High } \\
\text { susceptibility }\end{array}$ & $\begin{array}{l}\text { Wrażliwość } \\
\text { Susceptibility }\end{array}$ & $\begin{array}{l}\text { Słaba odporność } \\
\text { Weak resistance }\end{array}$ & $\begin{array}{l}\text { Średnia } \\
\text { odporność } \\
\text { Medium } \\
\text { resistance }\end{array}$ & $\begin{array}{c}\text { Wysoka } \\
\text { odporność } \\
\text { High resistance }\end{array}$ & $\begin{array}{c}\text { Średnia } \\
\text { śmiertelność } \\
\text { przy zalecanych } \\
\text { dawkach } \\
\text { Mean mortality } \\
\text { at recommended } \\
\text { doses } \\
{[\%]}\end{array}$ \\
\hline Beta-cyfluthrin & $\mathrm{X}$ & & & & & 100 \\
\hline Deltamethrin & $\mathrm{X}$ & & & & & 100 \\
\hline Esfenvalerate & $\mathrm{X}$ & & & & & 100 \\
\hline Etofenprox & $X$ & & & & & 100 \\
\hline Gamma-cyhalothrin & $\mathrm{X}$ & & & & & 100 \\
\hline Lambda-cyhalothrin & $\mathrm{X}$ & & & & & 100 \\
\hline Tau-fluvalinate & $\mathrm{X}$ & & & & & 100 \\
\hline Zeta-cypermethrin & $\mathrm{X}$ & & & & & 100 \\
\hline Tiacloprid & & $\mathrm{X}$ & $\mathrm{X}$ & & & $85-99$ \\
\hline
\end{tabular}

\section{Wnioski / Conclusions}

1. Mając wiedzę, że słodyszek rzepakowy i chowacz podobnik występują przez pewien okres czasu równolegle na roślinach rzepaku, a okres szkodliwości słodyszka rzepakowego przypada wcześniej niż okres szkodliwości chowacza podobnika, należy odpowiednio sterować ochroną chemiczną rzepaku.
2. Wykazane w badaniach różnice w poziomie odporności obu szkodników wskazują, że ochrona rzepaku jest zadaniem złożonym i wymaga stałego monitorowania poziomu odporności obu szkodników i na tej podstawie, opracowywania strategii ich zwalczania.

\section{Literatura / References}

Hansen L.M. 2008. Occurrence of insecticide resistant pollen beetles (Meligethes aeneus F.) in Danish oilseed rape (Brassica napus L.) crops. Bull. OEPP/EPPO Bull. 38 (1): 95-98. 
Heimbach U., Müller A., Thieme T. 2006a. First steps to analyse pyrethroid resistance of different oilseed rape pests in Germany. Nachrichtenbl. Pflanzenschutz. 58 (1): 1-5.

Heimbach U., Müller A., Thieme T. 2006b. First steps to analyse pyrethroid resistance of different oilseed rape pests in Germany: An extended abstract. IOBC/WPRS Bull. 29 (7): 131-134.

Malinowski H. 2003. Odporność owadów na insektycydy. Mechanizmy powstawania i możliwości przeciwdziałania. Wyd. Wieś Jutra, Warszawa, 211 ss.

Mrówczyński M., Pruszyński S. 2008. Integrowana produkcja rzepaku ozimego i jarego. Inst. Ochr. Roślin, Poznań, 107 ss.

Mrówczyński M., Węgorek P., Zamojska J., Pruszyński G., Wachowiak H. 2009. Porównanie wyników badań polowych i laboratoryjnych nad odpornością słodyszka rzepakowego (Meligethes aeneus F.) w Polsce. [Comparison of the results of laboratory and field studies concerning pollen beetle (Meligethes aeneus F.) resistance to insecticides in Poland]. Prog. Plant Prot./Post. Ochr. Roślin 49 (3): 1205-1210.

Nauen R. 2007. Insecticide mode of action, incidence and mechanisms of resistance. Presentation Abstract, EPPO Workshop on insecticide resistance of Meligethes ssp. (Pollen beetle) on oilseed rape. Berlin, 3-5 September 2007. www.archives.eppo. org/MEETINGS/2007 [Accessed: 19.11.2013].

Richardson D.M. 2008. Summary of findings from a participant country pollen beetle questionnaire. Bull. OEPP/EPPO Bull. 38 (1): $68-72$.

Węgorek P. 2009. Badania nad odpornością chrząszczy słodyszka rzepakowego (Meligethes aeneus F.) na insektycydy. Rozpr. Nauk. Inst. Ochr. Roślin - PIB 20, 122 ss.

Węgorek P., Mrówczyński M., Zamojska J. 2009. Resistance of pollen beetle (Meligethes aeneus F.) to selected active substances of insecticides in Poland. J. Plant Prot. Res. 49 (1): 119-127.

Zamojska J., Węgorek P., Mrówczyński M. 2010. Obecny poziom odporności na insektycydy dla wybranych gatunków owadów w Polsce. [Current status of a threat by resistance to insecticides of selected insect species in Poland]. Prog. Plant Prot./Post. Ochr. Roślin 50 (3): 1205-1212. 